\title{
Ensayo sobre la educación como convivencia para superar las escisiones
}

\author{
Essay on education as coexistence to overcome the scissions
}

William Roberto Darós ${ }^{1}$

\section{Resumen}

Se ha partido en este artículo del supuesto que convivencia significa vivir conscientemente en compañía. Se ha considerado que los seres humanos desean compañía, pero también autonomía o autodeterminación. Con una metodología propia de los ensayos, se ha considerado que la convivencia implica: a) Una relación con la satisfacción relativa y provisoria a través del intercambio; b) Más las diferencias (físicas, sociales, culturales, económicas, etc.), El bienestar de unos y el malestar de otros, llevan o pueden llevar a escisiones, grietas, separaciones, rupturas de la convivencia, que requieren superarse. Se ha planteado la hipótesis de que el proceso educativo personal y social, que respeta la libertad, la racionalidad y la afectividad es una herramienta necesaria pero quizás insuficiente, en un mundo que propone el hiperconsumo como ideal de vida.

Palabras clave: Convivencia; autodeterminación; valores comunes; hiperconsumo; escisiones.

\section{Abstract}

It has been started in this article from the assumption that coexistence means living consciously in company. It has been considered that human beings want company, but also autonomy or self-determination. With a methodology of trials, it has been considered that coexistence implies: a) A relationship with relative and provisional satisfaction through exchange; b) More differences (physical, social, cultural, economic, etc.), The well-being of some and the discomfort of others, lead or can lead to splits, cracks, separations, ruptures of coexistence, which need to be overcome. It has been hypothesized that the personal and social educational process, which respects freedom, rationality and affectivity is a necessar

Keywords: Coexistence, self-determination, common values, hyper-consumption, scissions.

1 Doctor en Filosofía, docente y secretario de Investigación y Desarrollo, Universidad del Centro Educativo Latinoamericano (UCEL). Correo electrónico: daroswr@yahoo.es; ; Id de Orcid: https://orcid.org/oooo-00o2-8475-3514 


\section{Introducción}

En este artículo nos movemos en la temática preocupada por la posibilidad de comprender y mejorar la convivencia humana. El tiempo se ha acelerado. Las modas cambian con cada estación y las generaciones duran cada vez menos tiempo. El cambio se ha vuelvo el clima natural en el que vivimos. En siglos anteriores, por el contrario, el tiempo tenía otro ritmo y orientarse resultaba ser posiblemente más fácil, firme y estable.

La convivencia, en el tiempo que nos toca vivir, se convierte en una tarea más compleja, cambiante, flexible; porque los seres humanos desean no sólo vivir (tener vivencias), sino también y en parte, convivir (convivencia): somos animales políticos, esto es, vivientes en una ciudad o polis. Quede claro, sin embargo, que se puede vivir con otros negativamente en constante agresividad mutua y exclusiones, como positivamente en constantes intentos de colaboración e inclusión.

Antiguamente se buscaban las cosas y amistades que durasen toda la vida; actualmente todo se licua: no hay nada permanente; se compra para tirar rápidamente lo comprado, y las amistades y la convivencia duran poco.

La convivencia deseada, positiva, no impuesta será humana si resulta ser el resultado de negociaciones, de intercambio de opiniones, valores y perspectivas de futuro. Lo que en la globalización se está imponiendo es la idea de una sociedad consumista que con sus ventas intenta abarcar todo el planeta, ignorando una gran parte de la humanidad que queda excluida de los goces de los centros de poder.

Lamentablemente, hoy pueblos enteros se trasladan desordenadamente, como emigrantes, abandonando con sus familias la tierra de sus padres y sus culturas para escapar de la muerte arbitraria en manos de grupos fanatizados por el hiperconsumo, la violencia y la corrupción. En este contexto se comprende que la violencia está siempre presente como una opción. Solamente un movimiento inclusivo y solidario puede encausar las necesidades humanas en un camino productivo no violento.

Materiales y método: Este ensayo hace su abordaje desde una hermenéutica de textos respecto a la convivencia humana en el proceso de significación histórico hasta nuestra contemporaneidad.

\section{Desarrollo}

\section{El concepto de convivencia}

En este artículo libro nos movemos con la temática preocupante de la posibilidad de comprender y mejorar la convivencia humana. 


\section{CIENCIAS SOCIALES}

El tiempo se ha acelerado. Las modas cambian con cada estación y las generaciones duran cada vez menos tiempo. El cambio se ha vuelto el clima natural en el que vivimos. En siglos anteriores, por el contrario, el tiempo tenía otro ritmo y orientarse resultaba ser más fácil, firme y estable.

La convivencia, en el tiempo que nos toca vivir, se convierte en una tarea más compleja, cambiante, flexible; porque los seres humanos desean no sólo vivir (tener vivencias), sino convivir (convivencia): somos animales políticos, esto es, vivientes en una ciudad o polis. Antiguamente se buscaban las cosas y amistades que durasen toda la vida; actualmente todo se licua: no hay nada permanente; se compra para tirar rápidamente lo comprado y las amistades y la convivencia duran poco.

Convivencia significa vivir conscientemente en compañía; tener la vivencia de vivir con los demás. Se trata de una terea nada fácil y cambiante con los tiempos. En el pasado se tuvo terror a los bárbaros; hoy se debe pasar a convivir con los inmigrantes extraños. Los seres humanos somos complejos y complicados. Por un lado, deseamos que nos ayuden y necesitamos de los otros o nos servimos de la bondad de los otros; pero por otro, deseamos tener autonomía, decisiones propias diferentes de la de los otros. Las relaciones sociales se articulan en torno a la idea de los otros como posibles poseedores de satisfactores de las necesidades de uno, y por tanto en relación con la satisfacción relativa y provisoria a través del intercambio (Heler, 2005). Mas las diferencias (físicas, sociales, culturales, económicas, etc.), el bienestar de unos (que gozan de las dádivas que otorga el Estado) y el malestar de otros (exprimidos por las retenciones del Estado), llevan o pueden llevar a escisiones, grietas, separaciones, rupturas de la convivencia.

Los supuestos fundamentales de la convivencia deseada, no impuesta, pueden ser descritos como un sistema ideal que pone de relieve la necesidad de las instituciones sociales, regidas por un conjunto de reglas que dirigen todas las operaciones de la sociabilidad y que tienen como objetivo remediar las continuas tendencias del poder a apartarse de los valores admitidos universalmente (o por la mayoría), valores tales como la justicia, la tolerancia y todos los derechos y deberes adquiridos por el hombre.

Por el contrario, la convivencia violenta impuesta será definida por la cohesión y el equilibrio de las relaciones interhumanas, obtenidos por la omnipresencia de la violencia, ya sea simbólica, ideológica o física, violencia ejercida abierta o sutilmente por la autoridad política para obtener la adhesión y la sumisión por la fuerza.

En este contexto, fácilmente se advierte que la convivencia deseada, no impuesta será el resultado de varias negociaciones, quizás inicialmente más o menos violentas, entre los deseos instintivos e individuales y las limitaciones que imponen los otros con similares deseos. Se trata de un arduo, flexible, constante balance y negociación 
entre los costos y los beneficios que se pueden lograr, pero sobre los que predomina el valor de la racionalidad y la justicia entre los considerados iguales.

En estas complejas relaciones de poder entre lo individual y lo social, entre lo instintivo y lo posible socialmente, entre el esfuerzo y las ganancias, entre la vida y presente y la descendencia futura, entre el egoísmo y el altruismo, la convivencia pacífica puede estar siempre en constante fragilidad; y será el resultado de un estado casi de tregua, donde las partes de nuestro ser y las de las demás personas sepan constatar las conveniencias recíprocas.

Es bastante simplificador, ingenuo y romántico, partir del supuesto de que los seres humanos son naturalmente buenos y la sociedad los corrompe. Antonio Rosmini, con más realismo sostenía que el querer bien a los otros en una sociedad parte siempre del interés por el bien propio:

En la benevolencia social, pues el hombre no se olvida de sí mismo, como en la amistad, sino que se considera y se ama como miembro de la sociedad. Es más, él se asocia con las otras personas únicamente por la ventaja que prevé le debe venir por esta asociación. Él no se apega a la asociación, no ama la sociedad, ni ama el bien común de la sociedad sino finalmente por su bien propio, por amor de sí mismo; ama el bien de los otros no propia y necesariamente porque es un bien de los otros, sino porque lo encuentra como una condición necesaria para su bien particular. La benevolencia social tiene, pues, un origen subjetivo: es el amor subjetivo que genera un amor objetivo, el cual sin embargo no ocupa en el corazón humano sino un lugar secundario (Rosmini, 1972: 152-153).

D. Dessein añade más matices al concepto de dificultades para la convivencia, aplicado a los argentinos.

... El argentino es un individuo, no un ciudadano. Ésta es la razón por la que el Estado le resulta una abstracción, de lo cual pueden desprenderse tres consecuencias. 1) La falta de compromiso político y social con todo lo que sea público (siempre es mejor quedarse en casa viendo fútbol). 2) Falta de conciencia fiscal ¿para qué hay que pagar impuestos?). 3) Falta de controles: como el Estado no es de nadie, se lo puede llenar de amigos -uno más ¿qué le hace? -, jtotal a nadie le importa! El argentino solo concibe una relación personal. Por eso, para él, robar dineros públicos no es un crimen (Dessein, 2003: 35). 


\section{CIENCIAS SOCIALES}

\section{Ser ciudadano es ser consumidor}

La justificación de la tendencia del hipercapitalismo contemporáneo a sustituir la posición del ciudadano por la del consumidor y la del legislador por la del empresario; y la tendencia a reducir la decisión política a una simple cuestión de gestión eficaz de los recursos y los bienes con el fin de satisfacer deseos y preferencias, conlleva una reducción de lo que es y de lo que puede ser el ser humano. Somos algo más de lo que comemos: los humanos somos seres problemáticos; buscamos un sentido para nuestras vidas, no renunciamos fácilmente a nuestros deseos, frecuentemente egoístas.

Además, toda comunidad crea su sentido y establece su red de imágenes y representaciones que se instituye como infra-poder, que desea perpetuar y absolutizarse a la manera de un mito o de la religión que se adueña de la institución de la convivencia. En el inicio de la Modernidad, esta red formó las identidades nacionales, no admitió las diferencias de religión, raza o color, la separación política y no soportó la alteridad sino como competencia y rivalidad. En la Posmodernidad tendemos hacia el otro extremo: nos agobia la identidad y se busca la diferencia, nos aplasta la comunidad y nos sumergimos en la individualidad en un cóctel de variedades.

Los ideales de justicia, igualdad, independencia, los horizontes espirituales de humanidad y los proyectos de felicidad y de cohabitación, esos principios de convivencia democrática ceden su lugar al ideal del consumo de una cantidad creciente de bienes materiales, cantidad, por otro lado, muy mal repartida. Desde la perspectiva de este nuevo orden, la mejor sociedad es la que produce y consume más. El hiperliberalismo económico ha empequeñecido el imaginario social, los ideales comunes, las representaciones culturales e incluso la acción política. ¿De la universalización o globalización nos encaminamos hacia la localización que cierra sus fronteras y crea muros?

La vivencia reclama la presencia y con-vivencia con otras personas. No solo necesitamos vivir y desvivirnos para satisfacer nuestras necesidades básicas; sino también implica desear el convivir. Convivir es una forma social de vivir que puede ser de sometimiento pasivo y resignado en medio de otros, o de indiferencia y prescindencia de los otros, o de colaboración con los otros con beneficios mutuos.

\section{Condiciones para la convivencia}

Primeramente, la convivencia con uno mismo supone la integralidad de las facultades (inteligencia y afectividad; razón y libertad, etc.), posibilidades, deseos, integrados en una armonía dinámica que la hace placentera. Sólo así se superan las situaciones de violencias y se convierten en potenciadoras de las personas. 
El narcisismo y el fanatismo nacen cuando no se es capaz de escuchar o de leer contextos diferentes ni de admitir que el otro posee o puede poseer valores que tal vez sería bueno adoptar; se originan cuando no es posible aceptar la autoridad ajena, es decir, cuando no es fácil reconocer que podemos adoptar algún producto que no hemos construido nosotros, cuando no podemos recordar y tener presente que hay cosas que han sido producidas por otros (Armengol; 2008, p. 26).

En poco tiempo, en menos de un siglo, varias causas hicieron que la sociedad cambiara no sólo velozmente, sino en su estructura cultural, en particular, en sus formas de vida.

El crecimiento demográfico mundial, juntamente con un mejor control de las epidemias, la capitalización de bienes, el pasaje de la industrialización a una era de la tecnología, y una generalización de la información, hicieron que la población mundial viviera de otra forma. Se ha cerrado la Modernidad y se ha pasado a la Posmodernidad. De la preocupación por vivir y sobrevivir a las grandes guerras mundiales y a la muerte inmediata, se ha pasado a un estilo de vida relativamente feliz para una parte de la humanidad y a la preocupación por el temor (desde el armamentismo atómico a al terrorismo del Estado y al terrorismo del fanatismo religioso) a la indiferencia e insignificancia en la posmodernidad (Bauman; 2015, p. 121) y a la preocupación por la con-vivencia.

Hasta hace poco tiempo, poblaciones enteras se trasladaban como inmigrantes a tierras de promisión dejando Europa. Hoy pueblos enteros se trasladan desordenadamente, como emigrantes, abandonando con sus familias sus reducidos bienes bombardeados, para escapar de la muerte arbitraria en manos de grupos de fanatizados, kamikazes, tras el ideal de imponer un nuevo renacimiento de un estilo de vida religioso y cultural, único y autoritario.

¿Cómo convivir, cuando la Europa tranquila y próspera, advierte que se reciente el bienestar logrado tras la colonización del mundo, ahora hecho dependiente, con medios pacíficos y audiovisuales, en un mundo a punto de suicidarse por el calentamiento global, gozado por los países ricos?

El miedo acompaña tanto a la pobreza como a la riqueza. El miedo, como el amor (Eros), nace -en el embriagante banquete de la vida- de la abundancia (Poros) y del deseo, búsqueda o privación (Penia): del miedo porque no se tiene o no se logra tener, como del poseer con abundancia y temer perder lo ya poseído. Sólo una persona y una nación que no desea razonablemente más de lo que tiene y no tiene más de lo que desea logra un relativo estado de plenitud temporario, de felicidad, de bienestar y bien vivir o convivir consigo mismo y con los demás. La mayoría de nuestros abuelos recordaron las privaciones de la premodernidad; la mayoría de nuestros padres vieron 


\section{CIENCIAS SOCIALES}

de cerca las posibilidades de relativo bienestar de la modernidad industrial; pero sus hijos se encaminan a beber apresuradamente los goces inciertos de la posmodernidad, abundante en juegos, distracciones bacanales, virtuales y adictivas, y escasa en reales posesiones. Los problemas se han hecho globales y los intentos de solución pretenden ser locales.

Para protegernos del miedo irracional, hemos creado un sistema legal (leyes) que nos asegure que tenemos derechos (que podemos hacer lo que es justo), pero no advertimos que los demás ciudadanos tienen igualmente derechos; y que, en consecuencia, tenemos al mismo tiempo el deber de respetar el derecho de los otros, lo que es básico para generar un régimen democrático de convivencia.

La condición primera de la democracia reside en la distinción e interrelación entre los individuos y la forma de gobierno de la comunidad. Se debe señalar primeramente que una de las características fundamentales de la modernización es la individualización de los valores y de la vida; es decir, el hecho de legitimar la acción y la responsabilidad del individuo, en vez de apelar a la responsabilidad de la colectividad. La individualización expresa, en realidad, una autonomía mayor de los individuos y funda toda voluntad de autodeterminación, que supone conocimiento, libertad y responsabilidad por los actos.

En ese sentido, la autodeterminación no expresa el aislamiento del individuo ni la afirmación de su egoísmo. Su separación con respecto a la totalidad se realiza por esta voluntad de autodeterminación. Por eso, el primer valor del individuo es poseer una intimidad propia, una separación con relación a la comunidad y a la totalidad. En cierta forma, esta separación le permite sustraerse a la sumisión total. Sabemos que la otra cara de la totalidad política es la disciplina, es el individuo normalizado, controlado, dominado e instrumentalizado. Por ello, la liberación del individuo se efectúa ante todo por esta separación con respecto a esa totalidad y por esta intimidad propia que da un sentido a su vida; pero también mediante una elaboración y aceptación de normas de convivencias sociales, crecientemente grupales e inclusivas, ardua tarea ésta, quizás nunca definitiva y constantemente sometida a revisión y negociación.

\section{Educar para la convivencia}

Jacques Delors, ya en el año de 1997, presentó un informe titulado "La Educación encierra un tesoro" propiciado por la Comisión Internacional para la Educación del siglo XXI de la UNESCO, en el informe se establecían los cuatro pilares que deben sustentar toda educación de calidad. Estos pilares están relacionados con la promoción de cuatro formas de aprendizaje: Aprender a aprender; Aprender a hacer; Aprender a ser y Aprender a vivir juntos. La necesidad de incluir además de los aspectos cognoscitivos e intelectuales, aspectos relacionados con el desarrollo personal y con las habilidades 
sociales resaltan la importancia que tiene para la educación el aprender a vivir juntos, es decir a "convivir" (Morales; 2011, 143).

No se debería confundir "instrucción" (ofrecer conocimientos) con "educación": ésta implica el logro de una formación de toda la persona y, socialmente, de todas las personas. La convivencia, cuando es adecuada, puede ser conceptualizada como un modo de vivir en relación o en interrelación con otros, en la cual se respeta y considera las características y diferencias individuales de las personas involucradas, independientemente de sus roles y funciones. La forma de convivir se aprende en cada espacio, en cada contexto en la que se comparte la vida con otros, inicialmente con la familia. Cuando ésta está ausente tenemos un grave problema social. A convivir se aprende y enseña conviviendo.

La convivencia, para que sea democrática, no sólo debe estar referida al conjunto de experiencias y conocimientos que se puedan compartir dentro de una estructura curricular, sino también es una manera de participar, opinar, discutir; es decir es una forma de vivir y construir una comunidad educativa.

La calidad es uno de los principios básicos de nuestro sistema educativo, está dirigida a asegurar las condiciones adecuadas para una educación integral, pertinente, abierta, flexible y permanente. Esta calidad de la educación requiere, por lo tanto, de una serie de factores que posibiliten la consecución de los objetivos: desarrollo de capacidades, actitudes y valores, y desarrollo de aprendizajes en los campos del saber, la cultura y el arte. Dentro de estos factores las relaciones humanas armoniosas constituyen un pilar importante para la calidad educativa.

En este contexto, una educación de calidad es aquella que establece objetivos socialmente relevantes, que logra que estos objetivos sean alcanzados por un mayor número de alumnos, que permite ayudarlos diferencialmente según sus requerimientos individuales y de su entorno sociocultural.

La calidad educativa supone, así mismo, un ambiente motivador y seguro y un clima socio-emocional proactivo que permite a los alumnos establecer relaciones interpesonales productivas; y a los docentes estimular a sus alumnos en su autonomía y a guiarlos en su desarrollo como personas.

La escuela es por lo tanto no solamente un escenario de instrucción, de adquisición de conocimientos, es también un ámbito de desarrollo personal y de aprendizaje social, de convivencia por lo cual hay que comprender que sus efectos no deben ceñirse a saberes concretos, sino también hay que visualizar y evaluar sus efectos en el desarrollo general de la personalidad individual y social de sus actores. 


\section{CIENCIAS SOCIALES}

Las instituciones educativas son sociedades de aprendizaje. Si la escuela no se preocupa por establecer un entorno seguro para que los alumnos asistan a la escuela sin miedo a ser agredidos, descuida el elemento fundamental que favorece el aprendizaje académico y la socialización de niños y jóvenes.

En el pasado, la educación adquiría muchas formas y demostró ser capaz de ajustarse a las cambiantes circunstancias, fijándose nuevos objetivos y diseñando nuevas estrategias. Pero, el cambio actual no es como los cambios del pasado. En ningún otro punto de inflexión de la historia humana los educadores debieron afrontar un desafío estrictamente comparable con el que nos presenta la divisoria de aguas contemporánea. Sencillamente, nunca antes estuvimos en una situación semejante. Aún debemos aprender el arte de vivir en un mundo sobresaturado de información y de inestabilidad afectiva. Y también debemos aprender el aún más difícil arte de preparar a las próximas generaciones para vivir en semejante mundo (Bauman; 2018, p. 21).

\section{La violencia rompe la convivencia}

Ante todo, ¿qué se entiende por violencia? El tiempo social y psicológico se ha acelerado. Las modas cambian con cada estación y las generaciones duran cada vez menos tiempo. El cambio se ha vuelvo el clima natural en el que vivimos. En siglos anteriores, por el contrario, el tiempo tenía otro ritmo y orientarse resultaba ser más fácil, firme y estable. La convivencia, en el tiempo que nos toca vivir, se convierte en una tarea más compleja, cambiante, flexible; porque los seres humanos desean no sólo vivir, sino convivir: somos animales políticos, esto es, covivientes en una ciudad.

El crecimiento y transformación de la violencia urbana ha hecho de este fenómeno uno de los más actuales e importantes de la ciudad de hoy. Hemos llegado a la alarmante situación de que prácticamente no hay dominio de la vida urbana donde las violencias no hayan penetrado y dejado sus efectos devastadores. La magnitud y características de la violencia urbana la han convertido en una de las preocupaciones ciudadanas prioritarias, en un factor de la calidad de vida de todos los sectores sociales que habitan las ciudades y en una de las expresiones más claras del nivel al que ha llegado la crisis urbana en nuestras ciudades. En 1950, el 41\% de la población vivía en ciudades, y en 1990 dicho porcentaje subió al 72\%. En el año 2000 eran el 76,8\%.

La crisis económica y las políticas de ajuste implantadas no sólo han generalizado la inseguridad social y económica, sino que han contribuido a reducir los mecanismos de representación, a restringir los espacios de solución de los conflictos, a mercantilizar las relaciones sociales, a restringir las manifestaciones culturales, propias de la condición de ciudadanía (Carrión; 2015).

La conflictividad urbana es una síntesis multicausal que provoca varios efectos, algunos de los cuales pueden asumir formas violentas ante la ausencia de canales de 
desfogue. Por lo tanto, el problema radica no en la conflictividad y sí en la inexistencia de canales institucionales para su procesamiento por vías pacíficas.

La violencia rompe, viola (quiebra por la fuerza) la situación de convivencia. La violencia se define como todo acto que guarde relación con la práctica de la fuerza física psicológica o verbal sobre otra persona, animal u objeto originando un daño sobre los mismos de manera voluntaria o accidental. El elemento principal dentro de las acciones violentas, es el uso de la fuerza tanto física como psicológica para el logro de los objetivos de dominación, y en contra de la víctima.

Ya en 1969, Galtung (2015) propuso una concepción amplia de violencia injusta y por tanto, de víctimas en sentido moral distinguiendo entre violencia directa, que implica relaciones interhumanas destructivas expresas, y violencia estructural, en la que la destrucción se encuentra en el funcionamiento objetivo de las instituciones, especialmente las económicas. En la primera, el sujeto violentador y su víctima aparecen manifiestamente. En la segunda, si bien puede detectarse a la víctima, los victimarios, que debe haberlos para que se trate de víctima moral, son difícilmente identificables, quedan difuminados.

Es víctima la persona que tiene desarrollos reales de sus posibilidades humanas manifiestamente inferiores a los desarrollos potenciales socialmente posibles; por ejemplo, aquella a quien se le acorta fuertemente la duración de su vida por problemas de subalimentación grave evitable o de falta de acceso a medicinas existentes.

La violencia es producto de una relación social conflictiva que surge de intereses y poderes que no encuentran soluciones distintas a la fuerza. Es un nivel de conflicto que no puede procesarse dentro de la institucionalidad vigente porque, por ejemplo, el sistema político está construido sobre la base de una representación social que tiene muchos vicios: la legitimidad de los gobernantes se erosiona rápidamente, el clientelismo como expresión de la privatización de la política- tiene sus límites y las relaciones de poder se fundan en la exclusión del oponente antes que, en la inclusión, el consenso, la concertación o el acuerdo.

Si bien no es fácil encontrar causalidades o determinaciones de la ciudad a la violencia, sí se puede afirmar categóricamente que la violencia no es exclusiva de la ciudad y que esta se comporta más bien como un escenario social más de aquella. Esto significa que la ciudad como tal no puede verse como determinante de la violencia.

La violencia común es una de las expresiones más claras de la inseguridad ciudadana. Sin embargo, los gobiernos locales y nacionales de la región y la propia sociedad aún no la han asumido con la debida propiedad, al extremo que el enfrentamiento al hecho delictivo arroja resultados más bien preocupantes. Instituciones fundamentales 
como la Policía y la Justicia se desacreditan a pasos agigantados y los habitantes se recluyen en un mundo privado cada vez más complejos.

Es necesario repensar, redefinir y fortalecer los espacios de socialización fundamentales de la sociedad urbana latinoamericana: la familia, la escuela, los medios de comunicación, la ciudad, etcétera, así como la creación de nuevos "lugares" y mecanismos institucionales para la solución de los conflictos, de pedagogía para la convivencia, la comunicación y la expresión de sentimientos.

El control, obviamente, no puede eliminarse, pero sí debe transformarse. Hay que establecer una estrategia de orden público democrático donde la Policía, la Justicia y los derechos humanos jueguen otro papel. Hasta ahora se ha enfrentado el problema de manera policial y con resultados no muy positivos. Se trata de un problema nacional de interés colectivo y público, que compromete al conjunto de la sociedad y sus instituciones (no sólo a la Policía). Sin embargo, siendo la ciudadanía la fuente y fin de la violencia urbana, se requiere su participación en la solución del problema. Pero también se deberá crear una nueva institucionalidad que la asuma, en la que bien podría participar la municipalidad por ser el órgano estatal más cercano a la sociedad civil y a la vida cotidiana.

\section{Trascender el punto de vista individual de la moral y elaborar el comportamiento social desde la niñez}

Vivir en convivencia, vivir con otros, en algunos intereses aceptados por todos y por los que deseen incluirse en una comunidad de convivencia. Se requiere dejar o consensuar el punto de vista de cada individuo con los otros puntos de vida de los demás socios de una comunidad que busca una convivencia razonable y no impuesta por la violencia externa en primera instancia. Esto implica un fuerte dominio de sí mismo en cada uno y es lo que suele faltar. Sin esto se cae en la utopía, en deseos irrealizables, en fantasías acerca de la igualdad, etc.

Requiere dejar como criterio la mera utilidad individual y dialogar, y construir unas normas y valores apreciados y aceptados por todos para poder convivir en paz y con justicia. Porque la justicia va a significar, entonces, vivir de acuerdo a leyes o normas, inicialmente aceptadas por todos y aplicables a todos por igual: el fruto de esta forma de vida será la paz y no la guerra o la violencia.

La universalización de las máximas e intereses problematizados, obliga a cada participante a trascender el contexto social e histórico de la forma de vida específica de cada uno de ellos y de su particular comunidad, de suerte que se adopte la perspectiva de todos los posiblemente afectados. 
Es esta operación la que, rebasando el horizonte del mundo de la vida específico de cada cultura dentro del cual se mueven los procesos éticos de autocomprensión, ofrece un criterio para discernir cuáles, de entre los plurales valores e intereses de los diversos sujetos y grupos, resultan en rigor intereses universalizables. O dicho en una palabra: esta operación ofrece un criterio normativo para enjuiciar imparcialmente las cuestiones de justicia (Ortega; 2016, pp. 832-833).

La teoría cognitivista de Kohlberg (1992), frente a otras vías de investigación psicológica de tipo conductista, psicoanalítico o sociológico, entiende la moralidad al modo de una construcción individual de principios autónomos, de suerte que su desarrollo aparece como el producto de una sistemática interacción entre las estructuras del sujeto y las estructuras del medio social a que dicho sujeto pertenece. Desde estas premisas, Kohlberg se esfuerza por demostrar, partiendo de Piaget, que existe una estructura o forma de pensamiento moral racional universal, lo que significa que dicha forma de pensamiento podría ser articulada por toda persona -aunque no lo sea de hecho- independientemente de su cultura. En este sentido presenta su teoría, empíricamente avalada mediante el método de entrevistas de respuesta libre a niños de diferentes condiciones, como una suerte de esquema cognitivo-evolutivo de la moralización del niño.

La ontogénesis hacia esta forma de pensamiento moral racional, -tal es la tesis cognitivo-evolutiva, acontece de forma universal, de manera que en todas las culturas el proceso de moralización pasa invariablemente por los mismos estadios, aunque evidentemente la organización socio-cultural potenciará o reprimirá, según el caso, unos u otros de estos estadios.

Los juicios morales, que el niño presenta en el nivel preconvencional, se organizan en dos estadios. En el primero, que Kohlberg denomina estadio de la orientación al castigo y la obediencia, el niño orienta su acción de acuerdo a una tendencia a evitar problemas. En el estadio segundo el niño se encuentra en un ingenuo hedonismo instrumental, en el que la acción correcta es aquélla que le reporta alguna forma de placer. Tal y como se expresa Kohlberg en "Del es al debe", en general en este primer nivel la acción justa es la que satisface instrumentalmente las necesidades del yo.

En el nivel convencional el valor moral reside en interpretar roles buenos o correctos, así como en mantener el orden y las expectativas de los demás.

Mientras que en el estadio tercero, el niño se orienta tratando de agradar a los miembros del grupo, de suerte que acontece aquí por vez primera la conformidad a imágenes estereotipadas de la mayoría; en el cuarto estadio se da ya una nítida orientación hacia el mantenimiento de la autoridad y del orden social dado. En términos generales, en el nivel convencional, el comportamiento justo consiste en cumplir con 
el deber propio, mostrar respeto por la autoridad y mantener el orden social dado porque es valioso en sí mismo.

Los juicios morales pronunciados por el adolescente en el nivel posconvencional se basan en la conformidad del ego con estándares, derechos o deberes compartidos o compartibles. En el estadio cinco, definido como legalismo contractual, el joven entiende el deber en términos de contrato, y se orienta evitando la violación de los derechos de otros y según la voluntad y bienestar de la mayoría.

El último estadio es el estrictamente posconvencional. La orientación del joven hacia la justicia no está marcada ya por las reglas que ordena la sociedad, sino por principios individuales de conciencia que requieren la llamada a una consistencia y universalidad lógica.

Kohlberg afirma que estos son principios universales de justicia, de reciprocidad e igualdad de los derechos humanos y de respeto por la dignidad de los seres humanos como individuos. Con estos supuestos es posible pensar, practicar y vivir en convivencia social.

La imparcialidad de los juicios morales queda asegurada mediante un principio de universalización que distingue como válidas todas y solo las normas que todos podrían querer. Él obra de tal manera que todos los demás podrían obrar como tú, se convierte en una norma moral universalizable para todos los integrantes de la sociedad y hace posible la convivencia. De esta manera se hace universal y natural la idea de justicia para todos y cada uno de los miembros de una sociedad, en todo tiempo y lugar. Parece ser, entonces que las tendencias hacia la cooperación y el altruismo, por así decirlo, no son un mero velo cultural, sino que los humanos han sido diseñados por la selección natural para ser gregarios y cooperativos.

El actuar conforme al amor al elogio o al miedo en la infamia favoreció la supervivencia del propio grupo frente a otros, realizándose así una convivencia naturalmente razonable. Sólo en un segundo momento el incremento de la rivalidad entre diversos grupos hizo emerger una conciencia grupal, específicamente humana, que extrapoló la antes individual motivación colaborativa a la vida del grupo en su conjunto, favoreciéndose la convivencia. Bajo el interés evolutivo de preservar la supervivencia en la convivencia con el grupo, la acción social humana fue transitando hacia una forma abstracta y normativa de cooperación, que marca la moralidad ya constituida del ser humano moderno.

\section{Generar un consenso social razonable}

Siguiendo la exposición de C. Ortega y Tomasello (2013, pp. 231-255), ya a una edad muy temprana, los niños aprenden a anticipar que serán juzgados por su comportamiento, 
lo que les incita a actuar de manera tal que incrementen las evaluaciones positivas y decrezcan las negativas que los demás sujetos tienen sobre ellos; es decir, a actuar colaborativa y prosocialmente para convivir humanamente. En un estadio más tardío, los sujetos comienzan a considerar a los demás como miembros de un grupo más amplio al que ellos mismos pertenecen, aprendiendo a valorar por sí mismas -y no ya por temor al castigo o por los imperativos específicos del adulto- las normas que el grupo se ha dado a sí mismo. Con este tránsito el niño se convierte, por así decirlo, en un sujeto plenamente socializado, capaz de convivencia libre y consciente; y, en este sentido, también en un sujeto y una convivencia moral.

En la medida en que los comportamientos altruistas son apreciados por la colectividad, y que los comportamientos egoístas son despreciados, los primeros suponen un incremento de la reputación social del sujeto que los realiza, mientras que los segundos suponen un incremento de la vergüenza social. Evidentemente, dentro de un grupo son los sujetos reputados los que tienen mayores posibilidades de reproducirse, y en este sentido el altruismo individual, que genera convivencia, parece poder explicarse también en los términos del éxito adaptativo. Sería, por así decir, una suerte de interiorización de normas de conducta basadas en la lógica de la reciprocidad indirecta.

Tal vez la figura del disidente político, cuya disidencia se fundamenta en una contradicción entre su concepción de la justicia y las normas socialmente establecidas, ejemplifique mejor que ninguna otra esa sustracción del comportamiento moral a la mera identificación con las normas, adaptativamente provechosas, que rigen dentro de un grupo social.

La concepción naturalista de la convivencia 1) según la cual los mandatos morales reflejan únicamente sentimientos de obligación que se pueden remitir a la interiorización de las sanciones con las que se nos ha amenazado (nivel preconvencional), 2) se supera con la concepción cognitivista razonable de que el interés recíproco en el cumplimiento de las normas se puede remitir en último término al interés por la propia estima (nivel convencional). La sanción, lo que el sujeto interioriza como sanción, es en verdad el miedo a la excomunión de una comunidad, a la ruptura de la convivencia, con la que está identificado. Evidentemente, esta lógica es en rigor la propia del nivel convencional.

Para solucionar consensualmente un conflicto y posibilitar la convivencia se requiere un punto de vista generador de consenso, y este punto de vista deriva de las propias estructuras de la interacción. El discurso ofrece al sujeto un lugar crítico, imparcial, desde el que someter a prueba las pretensiones de validez que, dándose ya implícitamente en toda praxis comunicativa cotidiana, han sido problematizadas por los participantes. Resulta extraordinariamente significativo que Habermas describa este tránsito al discurso como algo antinatural, en tanto implica una ruptura con la ingenuidad de las aspiraciones de validez formuladas, por lo que la convivencia no 


\section{CIENCIAS SOCIALES}

es simplemente estar juntos, sino desea consciente y libremente vivir con los otros, sin agresiones o violencia.

Con el paso al nivel posconvencional se introduce una actitud hipotética con respecto a las certidumbres previamente indiscutidas del mundo de la vida. La reflexión crítica despoja a este mundo de la vida de su índole originariamente natural, y la conformidad con los roles y normas sociales tradicionales queda remitida a las exigencias de justicia. La moral suministra los puntos de vista para proceder a un enjuiciamiento desencantador de las instituciones existentes. El proceso educativo (informal y formal) es fundamental para generar la conciencia y el valor de la convivencia entre humanos. La familia es el primer e irremplazable nicho para generar, aprender y enseñar afectiva y razonablemente la convivencia.

Ya desde la educación familiar, el discurso racional es un instrumento para la justificación crítica de normas, pero se requiere para justificar la convivencia el aprecio por ciertos valores y sentimientos humanos constructivos, como base para justificar un comportamiento conforme a las normas así fundamentadas.

Mas este fundamento y motivación psicológica y moral han de ser sostenidas tanto por el derecho, ante cuya coacción uno ya no tiene por qué preguntarse por los motivos para el cumplimiento de la norma; como por un modo de tradición que, siendo también fuente moral, adopte un carácter reflexivo; esto es, que haga depender la renovación de la tradición de la disposición a la crítica, y por tanto que impulse el cumplimiento de la norma moral cortada a la medida postconvencional.

La idea de justicia sólo puede extraerse de la forma ideal de una convivencia y reciprocidad realizada en el discurso. Sin la preparación para aceptar la racionalidad implicada en el discurso, en la discusión, no se logrará humanizar la idea de justicia, fundamental para elaborar la idea de una convivencia humana: se requiere y presupone el valor de las personas, como fines en sí mismas que se advienen a un consenso intersubjetivo de todos los afectados en un diálogo celebrado en condiciones de relativa simetría, lo que descarta la posibilidad de crear una convivencia humana fundada en la violencia.

La ausencia de esto, en este contexto, puede significar un sutil síntoma de la falta de racionalidad e insensibilidad moral de nuestra época para la convivencia humana.

La no percepción de signos tempranos de que algo amenaza o anda mal en el compañerismo humano y la viabilidad de la comunidad humana, y de que si no se hace nada, las cosas se pondrán aún peor, significa que la noción de peligro se ha perdido de vista o se ha minimizado lo suficiente como para inutilizar las interacciones humanas como factores potenciales de autodefensa comunitaria, y los ha convertido 
en algo superfluo, somero, frágil y quebradizo. A esto es a lo que, a fin de cuentas, realmente se reduce el proceso conocido como ‘individualización’ (resumido a su vez en el lema de moda 'Necesito más espacio', traducido como demanda para abolir la proximidad y la interferencia de los demás). Bauman (2017, p. 24).

Mas la convivencia no es una situación que se construye fácilmente, evitando sólo la violencia; se requiere además la difícil tarea de compartir valores semejantes. Frecuentemente se estima que los que no son como nosotros se debe a que no comparten conscientes y libremente los mismos valores.

L. Mead (2012; pp. 10-12) así piensa las raíces de la pobreza que se nota, por ejemplo entre los latinos y africanos y los norteamericanos, y no deja de repetirlo: lo que empuja a los norteamericanos decentes y "normales" a integrar un frente unido contra los desertores escolares, los criminales y los parásitos de la asistencia social, es la horrible incoherencia que perciben en todos ellos: los marginados ofenden los más preciados valores de la mayoría al mismo tiempo que se aferran a ellos, y pretenden disfrutar los mismos placeres de que gozan quienes se los ganaron trabajando. Dicho de otro modo: los estadounidenses normales guardan rencor a los marginados, porque los sueños y el modelo de vida de estos últimos son asombrosamente parecidos a los suyos. Y, sin embargo, esta semejanza no puede ser considerada una incoherencia. Como Peter Townsend apuntó, la lógica de la sociedad de consumo es formar a sus pobres como consumidores frustrados: "El estilo de vida de los consumidores es cada vez más inalcanzable para los sectores de bajos ingresos, históricamente definidos por una capacidad fija de compra que les permite asegurar su subsistencia o cubrir sus necesidades básicas" (Townsend; 2013, p. 73).

Las generalizaciones conspiran contra la comprensión de las situaciones concretas. Esto hace ver que la convivencia requiere una consideración a su vez singularizada y globalizadora de la experiencia humana. Queda implícito que la eliminación de la pobreza, si de algún modo fuera posible, no terminaría con el fenómeno de la marginalidad. Si es posible ser pobre y, a pesar de ello, "vivir dentro de los límites aceptados", entonces deben ser otros los factores por los que una persona termina en la clase marginada. Se pensó que esos factores podían ser carencias psicológicas y de comportamiento, quizás intensificadas en situaciones de pobreza y persecución, pero no determinadas por ellas.

\section{Agradecimiento}

Esta publicación obtuvo el financiamiento de: El Fondo de Asistencia Internacional de los Estudiantes y Académicos Noruegos, (SAIH). 


\section{Lista de referencias}

Armengol Millans, Rogeli (2008). El fanatismo, una perversión del narcisismo. Sobre el origen y la acción del superyó: reflexiones morales en Psicoanálisis, XX (1), pp. 26-38.

Bauman, Z. (2018). Los retos de la educación en la modernidad líquida. Edición virtual, ePub r1.o en: https://mega.nz/\#F!CbxnlAqZ!9VWeQQO1gEBJ8oCSzQ7p_g

Bauman, Z. - Donskis, L. (2017). Ceguera moral. La pérdida de sensibilidad en la modernidad líquida. Buenos Aires, Paidós.

Carrión M., Fernando (2015). De la violencia urbana a la convivencia ciudadana. Desco, Pretextos, Disponible en: http://works.bepress.com/cgi/viewcontent.cgi?ar ticle=1072\&context=fernando_carrion

Daros, W. R. (2001). Moralidad, el yo y la solidaridad social deseada, según R. Rorty en Invenio. $n^{\circ}$, p. 41-62.

Delich, F. (2014). La crisis en la crisis. Estado, Nación, Sociedad y Mercados en la Argentina contemporánea. Bs. As., Eudeba.

Dessein, D. (Comp.2013). Reinventar la Argentina. Reflexiones sobre la crisis. Bs. As., Sudamericana.

Etxeberria, Xabier (2016). El reconocimiento ético de las víctimas de la violencia del mercado en Pensamiento, vol. 72, $\mathrm{n}^{\circ} 274$.

Galtung, J. (2015). Sobre la paz. Barcelona, Fontamara.

Heler, Mario (2005). La seguridad y la utopía moderna de la convivencia. en Jornadas Ágora. Mar del Plata, 13 al 17 septiembre de 2005.

Kohlberg, L. (2012). Psicología del desarrollo moral. Bilbao, Desclée de Brouwer.

Mead, L. M. (2012) The New Politics of Poverty: The Nonworking Poor in America. Nueva York: Basic Books.

Morales, Luis Benites (2011). Convivencia escolar y calidad educativa" en Cultura, Lima (Perú), $n^{o}$ 25, p. 140-156.

Ortega, C. (2016). ¿Naturalizar la idea de justicia? Una respuesta crítica desde Habermas en Pensamiento, vol. 72, núm. 273 p. 832-833. DOI: https://doi.org/10.14422/ pen.v72.i273.y2016.004 
Rosmini, A. (1972). Filosofia della politica. Milano, Marzorati.

Townsend, P. (2013). Poverty in Europe, en Z. Ferge y S. M. Miller (comps.), Dynamics of Deprivation. Aldershot: Gower.

Tomasello, M. y Vaish, A. (2013). Origins of Human Cooperation and Morality, en: Annual Review of Psychology, Vol- 64, pp. 231-255. 